\title{
Total Kalça Protezi Takılan Meme Kanserli Yaşıı Kadının Evde Bakımı
}

\author{
Home Care of Elderly Women with Total Hip Prosthesis
}

\section{Kübra ERTURHAN TÜRK ${ }^{1}$, Hesna GÜRLER ${ }^{2}$}

\begin{abstract}
ÖZ
$\mathrm{Bu}$ çalışmada femur kırığ 1 nedeniyle total kalça protezi takılan yaşlı bir kadının Roper Logan Tierney Günlük Yaşam Aktiviteleri Modeline göre evde bakım gereksinimlerinin değerlendirilmesi ve bu gereksinimlere yönelik uygun girişimlerin planlanması amaçlandı. Bu çalışma bir olgu sunumudur. Total kalça protezi ameliyatı sonrası günlük yaşam aktivitelerinde yarı bağımlı olan birey yalnız yaşamakta ve evde bakım gereksinimlerini karşılayamamaktadır. Yapılan değerlendirmede bireye, günlük yaşam aktivitelerini yerine getirmede yetersizlik, konstipasyon, bilgi eksikliği, akut ağrı, uyku örüntüsünde bozulma, aktivite intoleransı, beden gereksiniminden az beslenme, sosyal izolasyon, beden imajında bozulma, rol performansında değişim, düşme ve venöz tromboemboli riski hemşirelik tanıları konuldu ve bu tanılara yönelik hemşirelik girişimleri uygulandı. Olgudan elde edilen veriler doğrultusunda Roper Logan Tierney Günlük Yaşam Aktiviteleri Modeli'nin günlük yaşam aktivitelerinde zorlanan yaşlı bireyin ameliyat sonrası evde bakım gereksinimlerinin belirlenmesi ve karşılanmasında yararlı bir model olduğu belirlendi.
\end{abstract}

Anahtar Kelimeler: Yaşlı, Evde Bakım, Total Kalça Protezi.

\begin{abstract}
The aim of this study was to evaluate the home care needs of an elderly woman with total hip replacement for femur fracture according to Roper Logan Tierney Daily Living Activities Model and to plan appropriate interventions for these requirements. This is a case report. After total hip replacement surgery, the individual who is half dependent on daily living activities lives alone and can't meet home care needs. During the assessment, knowledge deficit, body image disturbance, acute pain, disturbed sleep pattern, activity intolerance, nutrition less than body requirements, social isolation, constipation, inability to maintain daily living activities, risk of fall and risk of venous thromboembolism were identified as nursing diagnoses and nursing interventions for these diagnoses were performed. Roper Logan Tierney Daily Living Activities Model was found to be a useful model in determining and meeting the postoperative home care needs of elderly people who have difficulty in daily life activities.
\end{abstract}

Keywords: Elderly, Home Care, Total Hip Replacement.

*Bu çalışma 1. Uluslararası 5. Ulusal Ebelik Sempozyumunda sözel bildiri olarak sunuldu, 24-26 Nisan 2018, Sivas, Türkiye

${ }^{1}$ Arş. Gör., Sivas Cumhuriyet Üniversitesi, Sağlık Bilimleri Fakültesi, Hemşirelik Bölümü, Cerrahi Hastalıkları Hemşireliği, ORCID: 00000002-5393-8049

${ }^{2}$ Dr. Öğr. Üyesi, Sivas Cumhuriyet Üniversitesi, Sağlık Bilimleri Fakültesi, Hemşirelik Bölümü, Cerrahi Hastalıkları Hemşireliği, ORCID: 0000-0001-6641-9689

\begin{tabular}{|c|c|c|c|}
\hline İletişim / Corresponding Author: & Hesna GÜRLER & Geliş Tarihi / Received: & 30.10 .2018 \\
\hline e-posta/e-mail: & hesnagürler@hotmail.com & Kabul Tarihi/Accepted: & 28.01.2020 \\
\hline
\end{tabular}




\section{GİRISS}

Yaşlanma kronik hastalıklar ve bağımlılığın arttığı, kalıcı fonksiyonel sakatlıklar ve yaşam kalitesinde azalmanın eşlik ettiği normal ve dinamik bir süreçtir. ${ }^{1,2}$ Yaşlanma sürecinde ortaya çıkan fizyolojik değişiklikler ve hastalıklar sonucunda yaşlilar çeşitli risklerle karşılaşmakta ve bu risklerin başında düşmeler gelmektedir. ${ }^{2}$ Dünya genelinde her yıl 65 yaş üzeri bireylerin \%30-40'ının düş̧üğü ve yaş arttıkça bu oranın arttığı bildirilmektedir. ${ }^{2-4}$ Düşmeler olumsuz sağlik, ekonomik ve sosyal sonuçları olan evrensel bir problem ve geriatrik bir sendromdur. ${ }^{4,5}$ Yaşlilık döneminde görülen her 10 düşmeden biri kalça kırı̆̆ı ya da kafa travması gibi ciddi yaralanmalara neden olmaktadır., ${ }^{3,6}$ Düşme sonucu ortaya çıkan kalça kırıkları hastaneye yatışı gerektiren, yaşlının yaşam kalitesini bozan, fiziksel aktivitede azalma, bağımsızlık kaybı ve kalıcı sakatlıklara neden olan en sıkıntılı yaralanmalardır. ${ }^{1}$

Yaşlılık döneminde meydana gelen kalça kırıklarının tedavisinde en s1k tercih edilen yöntem total kalça protezidir (TKP). ${ }^{7}$ TKP ameliyatı bireyin yaşam kalitesini etkileyebilecek ve hastaneye yatışlara neden olabilecek çok sayıda komplikasyona neden olmakla birlikte, ${ }^{8,9}$ bağımlı olma, günlük yaşama uyum sağlayamama ve rol ve sorumlulukları yerine getirememe gibi endişelere de yol açmaktadır. ${ }^{9}$ Cerrahi girişim sonrası iyileşme süreci kompleks bir dönemdir ve bu dönemde birey beklenmedik stresli olaylarla karşılaşabilir. ${ }^{10} \mathrm{Bu}$ nedenle TKP uygulanan yaşlı bireylerin komplikasyonlar yönünden riskli olduğu ve iyileşme sürecindeki bakımın önemli olduğu, özellikle ilk bir aylık dönemde bağımsızlıklarının yeniden kazandırılması, olası komplikasyonların önlenmesi ve yaşam kalitelerinin artmasında taburculuk sonrası evde bakım önemlidir. ${ }^{9,11}$ Ancak yapılan çalışmalarda hastaların taburculuk sürecinde yeterince bilgilendirilmemeleri nedeniyle evde bakım gereksinimlerini karşılayamadıkları bildirilmektedir. ${ }^{10,12}$

Cerrahi girişim uygulanan yaşlı bireylerde günlük yaşam aktiviteleri ile ilgili problemlerin önlenmesi, azaltılması ve çözümlenmesinde bireyselleştirilmiş Günlük Yaşam Aktiviteleri Modelinin kullanılması önemli bir uygulamadır. ${ }^{13-15}$ Roper, Logan ve Tierney tarafından 1970 yılında geliştirilen model bireyi bir bütün olarak tanımayı, bireyin yaşadığ 1 problemleri belirleyip çözmeyi sağlamakta ve bireye holistik bakım vermeyi amaçlamaktadır. ${ }^{16}$ Model; güvenli çevrenin sağlanması ve sürdürülmesi, iletişim, solunum, beslenme, boşaltım, bireysel temizlik ve giyim, beden 1sısının denetimi, hareket, çalışma ve eğlenme, cinselliği ifade etme, uyku, ölüm dahil olmak üzere 12 alt başlıktan oluşmaktadır. ${ }^{14}$ Günlük yaşam aktiviteleri modeli alt boyutları dikkate alınarak, evde yalnız yaşayan, yaşlı ve kanser hastası olan olgunun, cerrahi girişim nedeniyle evde günlük yaşam aktivitelerini yerine getirmekte zorlandığ 1 ve iyileşme sürecinde komplikasyon gelişmesi açısından riskli olduğu düşünüldü. $\mathrm{Bu}$ nedenle, bu çalışmada femur kırığı nedeniyle total kalça protezi takılan meme kanserli yaşlı bir kadının Roper, Logan, Tierney Günlük Yaşam Aktiviteleri Modeline göre evde bakım gereksinimlerinin değerlendirilmesi ve bu gereksinimlere yönelik uygun girişimlerin planlanması amaçland1.

\section{OLGU SUNUMU}

\section{Veri Toplama}

Veri toplama 1 Eylül 2017 ile 13 Ekim 2017 tarihleri arasında yapıldı. Araştırmada Helsinki Bildirgesi'nde yer alan etik ilkelere uyuldu. Hasta ve aileye gerekli bilgilendirmeler yapıldı ve sözel onam alındı.

\section{Olgu}

Çalışmada bir yıl önce meme kanseri tanısı konularak modifiye radikal mastektomi uygulanan, 6 kür kemoterapi alan ve baş dönmesine bağlı evde yürürken düşerek femuru kırılan bir kadın hasta sunulmaktadır. 
Düşme sonrası acil sağlık ekipleri tarafından hastaneye götürülen 76 yaşındaki olguya femur kırığ 1 tanısı konularak total kalça protezi takıldı ve 10 gün sonra hastaneden taburcu edildi. Hastanede yapilan değerlendirmede bireyin 5 yıl önce eşinin öldüğü, hiç çocuğu olmadığı, evde yalnız yaşadığı, evde bakımı konusunda kendisine yardımcı olacak sadece yeğeni olduğu ve onunda her zaman gelemeyeceği bilgisine ulaşıldı. Taburcu olduktan 3 gün sonra hasta ile telefonda görüşüldü, bireyin evde bakım gereksinimlerini karşılayamadığı belirlenerek kapsamlı değerlendirme amaciyla taburculuk sonrası 1. haftada ev ziyareti yapıldı. Günlük Yaşam Aktiviteleri Modeli kullanılarak yapılan değerlendirmede hastanın yaşam aktivitelerine ilişkin bağımlılık ve bağımsızlık durumu değerlendirildi (Şekil 1). Bunun sonucunda bireyde günlük yaşam aktivitelerini yerine getirmede yetersizlik, konstipasyon, bilgi eksikliği, akut ağrı, uyku örüntüsünde bozulma, aktivite intolerans1, beden gereksiniminden az beslenme, sosyal izolasyon, beden imajında bozulma, düşme ve venöz tromboemboli riski hemşirelik tanıları ele alındı ve bu tanılara yönelik hemşirelik girişimleri uygulandı. Birey ilk ev ziyaretinden 2 hafta sonra tekrar ziyaret edildi ve mevcut problemlerin ortadan kalkma durumu değerlendirildi. Birey değerlendirmenin yapıldığı dönemde herhangi bir komplikasyon nedeni ile hastaneye başvurmadi.

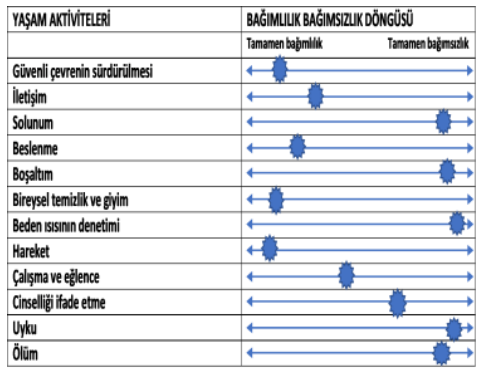

Şekil 1. Bireyin Günlük Yaşam Aktivitelerine Özgü Bağımlılık Durumu

Günlük Yaşam Aktiviteleri Modeline Göre Örnek Bakım Planı

\section{Güvenli Çevrenin Sürdürülmesi}

Yaşam aktivitesine ilişkin veri: 10 puanlık Numerik Derecelendirme Ölçeği'ne
(Numeric Rating Scale, NRS) göre ameliyat bölgesindeki ağrıya 7 , genel vücut ağrısına 5 puan vermesi.

Hemşirelik tanısı 1: Akut ağrı

Amaç: Hasta ağrısının olmadığını ifade edecek/NRS skalasina 0-3 arasinda puan verecek

\section{Girişim/Gerekçe}

- Ağrının yeri, süresi, yoğunluğu, artıran ve azaltan faktörler belirlenir/Tedavi planına yön verir.

- Ağrı skalası üzerinde 0'dan 10'a kadar ağrısına puan vermesi istenir/Tedaviyi yönlendirir ve etkinliğini değerlendirir.

- Dünya Sağlık Örgütü ağrı basamağına göre kendisine taburcu olurken reçete edilen analjezik uygulanır/A $\breve{g} r$ şiddetine uygun tedaviyi seçmeye yardım eder.

- Non-farmakolojik müdahaleler uygulanır/Kapı kontrol mekanizmasinin devreye girmesini sağlar.

- Hastanın ağrısı ilaç uygulamasından 1 saat sonra ve her 2-4 saatte bir kontrol

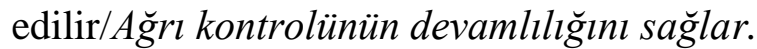

Değerlendirme: Hasta ameliyat bölgesindeki ağrı şiddetinin 1'e, genel vücuttaki ağrı şiddetinin ise 2'ye düştüğünü ifade etti.

Yaşam aktivitesine ilişkin veri: Total kalça protezinin olması, düşme öyküsü, baş dönmesi, yardımcı araç kullanımı, ev ortamının güvenilir olmaması.

Hemşirelik tanısı 2: Düşme riski

Amaç: Hasta düşmeyecek.

\section{Girişim/Gerekçe}

- Güvenli çevre oluşturulur (dağınıklık, mobilya düzenlenmesi vb.)/Dağınık eşyalar ayak takılmasına yol açarak düşmeye neden olabilir.

- Kademeli

mobilizasyon yap1lır/Ortostatik hipotansiyonu önler.

- Birey ve bireyin bakımında destek olan aile üyesine gece lambası kullanılması, kilimlerin kaldırılması, tuvalet ve banyonun 
kaygan olmaması ve banyoda tutma yerlerinin olmasi konusunda bilgi verilir/Olası düşmeleri önler.

- Yatak en alçak seviyede tutulur/Yatağın düşük konumda tutulması yataktan çıkarken yaralanma veya düşme riskini azaltır.

- Yürürken yardımcı araç kullanımı konusunda bilgilendirilir/Destek sağlar ve düşmeyi önler.

- Bireyin kullandığ1 ilaçların yan etkileri değerlendirilir/Bazı ilaçlar düşmelere neden olabilir.

Değerlendirme: Birey kapıyı açmaya giderken acele etmesi nedeni ile bir kez yaralayıcı olmayan düşme yaşadığını ifade etti.

\section{İletişim}

Yaşam aktivitesine ilişkin veri: 76 yaş, meme kanseri olması, yalnız yaşaması, hastanın bakımını kardeşinin çocuğunun üstlenmesi, komşuları ve akrabaları ile görüşememesi, total kalça protezi nedeni ile yarı bağımlı hale geldiğini ifade etmesi.

Hemşirelik tanısı 3: Sosyal izolasyon

Amaç: Hasta izolasyon duygusunu tanımlayacak ve izolasyonu yönetecek, faaliyetlere aktif katılacak.

\section{Girişim/Gerekçe}

- Hasta sosyal izolasyon yaşamasına neden olan faktörler konusunda gözlemlenir/Nedeni bilmek hemşirenin uygun tedaviye karar vermesini sağlar.

- $\quad$ Aile üyeleri ile görüşülerek birey için sosyal etkileşime girme olanakları sağlanır/Farkl aktivitelere hastayı katmak daha az izole hissetmesini sağlar.

- Hasta başkaları ile konuşma başlattığında olumlu geri bildirim verilir/Hemşireden gelen olumlu geri bildirimler hastayla güven ilişkisini pekiştirir.

- Destek grupları hakkında bilgi verilir ve onlarla iletişime geçmeye teşvik
edilir/Aynı sorunu yaşayan kişilerle bir araya gelmek hastanın daha iyi baş etmesine yardımcr olabilir.

Değerlendirme: Birey ağrısının azalması nedeni ile yeğeninin desteğiyle aile-arkadaşkomşu ziyareti yapabiliyor.

Yaşam aktivitesine ilişkin veri: Total kalça protezi ve olası komplikasyonlar konusunda bilgi eksikliğinin olmaması.

\section{Hemşirelik tanısı 4: Bilgi eksikliği}

Amaç: Bireyin total kalça protezi ve olası komplikasyonlar konusunda yeterli bilgisi olacak.

\section{Girişim/Gerekçe}

- Birey ve yeğeni bacak bacak üstüne atmama, ayakkabı/çorap giyerken kalçayı bükmeme, alçak ve sallanan koltuklarda oturmama, alafranga tuvalet kullanma, yatarken dizlerinin arasına küçük bir yastık koyma gibi konularda bilgilendirilir/Protez dislokasyonunu önler.

- Total kalça protezinin olası komplikasyonları ve bu komplikasyonların bulgular1

bilgilendirilir/Komplikasyonları erken belirlemeye yardım eder.

- Kontrol zamanı konusunda hatırlatma yapılır/Tedavi süreci hakkında bilgi edinmeyi sağlar.

Değerlendirme: Birey protez dislokasyonunu önleyen uygulamalar ve total kalça protezinin diğer olası komplikasyonları hakkında bilgi sahibi oldu.

\section{Solunum}

Yaşam aktivitesine ilişkin veri: Solunumla ilişkili herhangi bir problemi yok, solunum sayıs $20 / \mathrm{dk}$.

\section{Beslenme}

Yaşam aktivitesine ilişsin veri: Beden Kitle İndeksi: $26 \mathrm{~kg} / \mathrm{m}^{2}$, iştahsızlık ve bulantı problemi nedeni ile yeterince beslenememe, yemek yapamadığı için yeğeni yemek getirdiğinde yemesi. 
Hemşirelik tanısı 5: Beden gereksiniminden az beslenme

Amaç: Hasta yeterli miktarda ve dengeli beslenecek.

\section{Girişim/Gerekçe}

- Hasta ne zaman ve ne yiyeceğini seçer. Hasta istemediği durumda yemek yemeye zorlanmaz/Amaç öncelikle yeterli beslenmeyi sağlamak yerine hastayı rahat ettirmektir.

- Yemek sirasinda hasta dik oturtulur/Hastanin yutmasina ve aspirasyonun önlenmesine yardımcı olur.

- Hastanın kilosu izlenir/Sürece иуити takip edilir.

- Yaşam bulguları ve laboratuar bulguları izlenir/Yetersiz beslenme durumunu ve yetersiz beslenme sonucunda ortaya çıkan elektrolit dengesizliği ile ilişkili kardiyak fonksiyondaki değişimleri belirler.

- Güven oluşturucu yaklaşım sergilenir/Hasta tarafindan kabulü geliştirir.

- Keyifli yeme çevresi sağlanır ve alımları kayıt edilir/Hastanın beslenmesini geliştirir.

- 6 küçük öğün ve hafif yemekler sağlanır/Gastrik dilatasyonu önler.

- Bulantıs1 giderilir/Yeterli beslenmeyi sağlar.

Değerlendirme: Birey mide bulantıs1 yaşamadığı için 3 ana 2 ara öğün besleniyor.

\section{Boşaltım}

Yaşam aktivitesine ilişskin veri: Sürekli yatak içerisinde durma, hareket etmeme, 5 gündür defekasyona çıkmama, bağırsak seslerinin 1-2/dk olması, günlük 500-750 ml s1v1 almasi.

Hemşirelik tanısı 6: Konstipasyon

Amaç: Hasta 1-3 günde bir normal şekilde ve kıvamda defekasyona çıkacak.

\section{Girişim/Gerekçe}

- Bireyde konstipasyona neden olabilecek beslenme, siv1 alımı, hareket, ilaçlar ve laksatiflerin kullanımı gibi risk faktörleri değerlendirilir/Konstipasyona katkıda bulunan faktörler tanımlanır.

- Defekasyon için belirli bir zaman ayarlaması söylenir/Refleksi kolaylaştırır.

- Taze meyveler, sebzeler ve kepekli tahıllar içeren yüksek lifli bir diyet sağlanır/Lifli diyetin artması barsak motilitesi ve kas tonusunu artırır.

- Kontrendike değilse günde 2-3 L siv1 alması söylenir/Gaitanın özelliğini yumuşatır.

- Hastanın ev içinde destekli yürüyüşleri sağlanır ve abdominal egzersizler düzenlenir/Spontan defekasyonu sağlar, kas tonusunu geliştirir, peristaltizmi hızlandırır.

- Gerektiğinde gaita yumuşatıcılar veya laksatifler uygulanır/Gaitanın ilerlemesini kolaylaştırır.

Değerlendirme: Bireyin sıvı alımı 1500 $\mathrm{mL}$, bağırsak sesleri $6 / \mathrm{dk}$, iki günde bir zorlanmadan defekasyona çıkıyor.

\section{Bireysel Temizlik ve Giyinme}

Yaşam aktivitesine ilişkin veri: Banyo, yemek yapma, giyinme aktivitelerinde yarı bağımlı olma.

Hemşirelik tanısı 7: Günlük yaşam aktivitelerini yerine getirmede yetersizlik

Amaç: Hasta günlük yaşam aktivitelerini olabildiğince bağımsız gerçekleştirecek.

\section{Girişim/Gerekçe}

- Hastanın bağımsız neler yapabildiği değerlendirilir/Hastanın katılım potansiyeli, yapabileceklerine bağlıdir.

- Hasta kendi hizına göre hareket etmeye teşvik edilir/Hasta aktiviteleri gerçekleştirmek için daha fazla zamana ihtiyaç duyabilir. 
- Ailenin bakıma katılması teşvik edilir/ Ailenin bakıma dahil edilmesi iletişimi güçlendirir ve destek sağlar.

- Günlük yaşam aktivitelerinde yapamadığı noktada destek olunur/Günlük yaşam aktivitelerini yerine getiremediği durumlarda kişinin kendini rahat hissetmesi ve olası problemlerin önlenmesini sağlar.

Değerlendirme: Bireyin banyo ve yemek yapma günlük yaşam aktivitelerini yerine getirmede yetersizliği devam ediyor.

\section{Vücut Sıcaklığının Kontrolü}

Yaşam aktivitesine ilişkin veri: Vücut sicaklığg $36.3^{\circ} \mathrm{C}$.

\section{Hareket}

Yaşam aktivitesine ilişkin veri: Hastanın sürekli yatak içerisinde durması, sadece tuvalet ihtiyacını karşılamak için mobilize olmas1, mobilize olduğunda koltuk değneği kullanması, daha önce düşme öyküsünün olması, mobilizasyon sırasında ağrı ve dispne yaşaması.

Hemşirelik tanısı 8: Aktivite intoleransı

Amaç: Aktivite düzeyini kademeli olarak artıracak/Ağrı ve dispne olmadan hareket edebilecek.

\section{Girişim/Gerekçe}

- Mobilizasyon öncesi ve sonras1 yaşam değerlendirilir/Mobilizasyonun bulgular1 bulguları üzerindeki etkisini belirler.

- Hastanin ağr1 düzeyi izlenir/Gelecekteki değerlendirmelere temel oluşturur.

- Aktiviteden önce ağrı azaltılır/Aktivite seviyesinde bir artış sağlar.

- Mümkün olduğu kadar bağımsızlığg desteklenir/Aktiviteyi teşvik eder.

- Kademeli mobilizasyon yapılır/Ortostatik hipotansiyonu önler.

- Hemşirelik müdahaleleri uygun şekilde gruplandırılır/Hasta eforunu en aza indirir.
- Disiplinler arası ekiple işbirliği yapılır/Sağllk ekibinin diğer üyelerinden destek alınmasi hemşirelik girişimi ile çözümlenemeyen problemlerde olası çözüm yollarının bulunmasını kolaylaştırır.

Değerlendirme: Birey ağrı ve dispne yaşamadan mobilize olabiliyor.

Yaşam aktivitesine ilişkin veri: Hastanın sürekli yatak içerisinde durması, sadece tuvalet ihtiyacını karşılamak için mobilize olmas1, mobilize olduğunda koltuk değneği kullanması, daha önce düşme öyküsünün olması, mobilizasyon sırasında ağrı ve dispne yaşaması.

Hemşirelik tanısı 9: Venöz tromboemboli riski

Amaç: Venöz tromboemboli gelişmeyecek.

\section{Girişim/Gerekçe:}

- Bireyin mobilizasyonu sağlanır/Kas pompasını aktifleştirir.

- Mobilizasyonu etkileyen durumlar belirlenir/Nedene yönelik planlamalar yapmaya yardım eder.

- Yatak

içi sağlanır/Venöz dönüşü kolaylaştırır.

- Venöz tromboembolinin ayaklarda kızarıklık, ödem, sıcaklık artışı gibi bulguları izlenir ve hasta bulgular konusunda bilgilendirilir/Tedavi planını uygulamayı sağlar.

- Antitrombotik

tedavi uygulanır/Trombositlerin agregasyonunu önler.

Değerlendirme: Bireyde venöz tromboemboli gelişmedi.

\section{Çalışma ve Eğlence}

Yaşam aktivitesine ilişkin veri: Gün içerisinde yalnızca televizyon izleme, boş zamanları değerlendirmek için herhangi bir aktivitede bulunmama, rollerini tek başına yerine getirememe.

Hemşirelik tanısı 10: Rol performansında değişim 
Amaç: Hasta temel rolleri gerçekleştirmek için yeni yollar belirleyecek.

\section{Girişim/Gerekçe}

- Hastanın kendi rolleri ile ilgili endişelerini dile getirmesine izin verilir/Hasta için olası rol sorunlarının netleştirilmesine yardımcr olur ve bir plan geliştirme sürecine başlayabilmeyi sağlar.

- Kaynakları tanımlamak için hasta ve ailesine yardım edilir/Total kalça protezi olan hastada kişilerarası ilişkiler önemli ölçüde etkilenebilir. Arkadaşlar ve aile duygusal ve fiziksel yardım sağlayabilir.

- Hastanın uygun fiziksel desteğe erişmesine yardımcı olmak için bir sosyal çalışana ve aileye danışı1ır/Total kalça protezi hastanın ihtiyaçlarına erişimi zorlaştırır.

- Bölge destek grupları hakkında bilgi verilir/Benzer deneyimlerden geçen bireyler hasta ve aile için destek ve bilgi sağlayabilir.

Değerlendirme: Bireyin rol performansında değişim devam ediyor.

\section{Cinselliği İfade Etme}

Yaşam aktivitesine ilişkin veri: Eşinin olmamas1, mastektomi nedeni ile kıyafetlerinin üzerinde güzel durmadığını, meme dokusu çıkarıldığı ve saçları döküldüğü için kendini kadın gibi hissetmediğini, kendini ve bedeninin hiçbir bölümünü beğenmediğini ifade etmesi.

Hemşirelik tanısı 11: Beden imajında bozulma

Amaç: Hasta bedeni ile ilgili memnuniyetini açıklayacak.

\section{Girişim/Gerekçe}

- Hastanın kendi bedeniyle ilgili sözel ve sözsüz cevapları değerlendirilir/Hastanın beden algısının anlaşılmasını sağlar.

- Tedavi ve sürece ilişkin kaygıları kabul edilir ve hasta dinlenir/Teröpatik ilişki kurmayl sağlar.
- Kendi hakkındaki negatif ifadeleri izlenir/Müdahalelerin hastaya yardım edip etmediğini belirler.

- Sosyal hizmetlere yönlendirilir ya da bu konuda danışmanlık yapılır/Psikososyal konularda hastaya yardim eder.

- Önyargısız bir davranışla bakım sağlanır/Hastanın saygınlığını sürdürür.

Değerlendirme: Birey sağlık durumunun dış görünüşünden daha önemli olduğunu, meme kaybını eskisi kadar önemsemediğini ve bedenini kabul etmeye başladığını ifade etti.

\section{Uyku ve Dinlenme}

Yaşam aktivitesine ilişkin veri: Gün içerisinde uyuklamalarının olması, günde 5-6 saat uyuması, uykularında bölünmeler olduğunu, sabah dinlenmiş uyanmadığını ve yorgun hissettiğini, ağrısı nedeni ile uyuyamadığını ifade etmesi.

Hemşirelik tanısı 12: Uyku örüntüsünde bozulma

Amaç: Hasta günde 8 saat uyuyacak/Uyandığında kendisini dinlenmiş hissedecek.

\section{Girişim/Gerekçe}

- Uyuma konusundaki engeller belirlenir/Hastada var olan anksiyete ve ăgrt uykuyu zorlaştırabilir.

- Sessiz ve huzurlu bir ortam sağlanır/Hastanın uykuya dalmasına yardimcl olur.

- Ağrı azaltılır (Akut ağrı tanısı içinde)/Sempatik stimülasyonu azaltır.

Değerlendirme: Gün içerisinde uyuklamaları ve yorgunluğu azaldı. Birey ağrıları azaldığı için daha iyi uyuduğunu ifade etti. Günlük 7 saat uyuyor.

\section{Ölüm}

Yaşam aktivitesine ilişkin veri: Ölümle ilişkili herhangi bir korkusunun olmadığını ifade etmesi. 


\section{BULGULAR VE TARTIŞMA}

Olgu sunumu olarak ele alınan bu çalışmada, meme kanseri nedeni ile modifiye radikal mastektomi uygulanan ve femur kırığı nedeniyle total kalça protezi takılan 76 yaşında bir kadının taburculuk sonrası evde bakımına ilişkin Roper, Logan, Tierney Günlük Yaşam Aktiviteleri Modeline göre hazırlanmış bakım planı ele alındı.

Yaşlanma sürecinde ortaya çıkan fizyolojik değişiklikler ve kronik hastalıklar yaşlı bireylerde ameliyat sonrası iyileşmenin uzamasına ve komplikasyon gelişmesine neden olmaktadır. ${ }^{1,17}$ Cerrahi girişim uygulanan yaşlı bireylerin komplikasyonlar yönünden riskli ve iyileşme sürecindeki bakımın önemli olduğu özellikle ilk bir aylık dönemde evde yaşadıkları problemlerin belirlenmesi ve bu problemlere yönelik girişimlerin planlanması gelişebilecek olası problemlerin önlenmesinde önemli bir basamaktır. ${ }^{11}$ Yapılan çalışmalarda TKP uygulanan yaşlı bireylerin taburculuk sonrası ilk bir ayda çok sayıda problem yaşadığ $1^{9,18-21}$ ve hastaların \%56'sinda yeni bir cerrahi girişim gerektiren komplikasyon geliştiği bildirilmektedir. ${ }^{18}$ TKP sonras1 hasta deneyimlerini araştıran çalışmalarda bireylerin taburculuk sonrasi 1-4. haftalarda protez ve ağrı kaynaklı hareket etme kısıtlılığı, günlük yaşam aktivitelerini yerine getirmede zorlanma ve konstipasyon yaşadıkları belirlenmiştir. ${ }^{9,18-21}$ Total kalça protezi ameliyatı uygulanan olgumuzda da literatürü destekler nitelikte taburculuk sonrası birinci haftada, günlük yaşam aktivitelerini yerine getirmede yetersizlik, düşme riski, aktivite intoleransı, akut ağrı, bilgi eksikliği, konstipasyon, uyku örüntüsünde bozulma ve beden gereksiniminden az beslenme gibi problemler yaşadığ1 ve bireyin yeniden düşme ve venöz tromboemboli gelişme riski olduğu belirlendi.

TKP, bireyleri fiziksel olduğu kadar psikolojik, sosyal ve spiritüel boyutları ile de etkileyen bir girişimdir. ${ }^{22}$ Total kalça protezi uygulanan hastaların taburculuk sonrası deneyimlerinin araştırıldığı bir çalışmada, bireylerin taburculuk sonrası evde bakım gereksinimlerinin yeterince değerlendirilmediği ve bu nedenle hayal kırıklığı, terk edilmişlik, sosyal izolasyon ve yalnızlık duyguları yaşadıkları belirlenmiştir. ${ }^{10}$ Yapılan benzer çalışmalarda da total kalça protezi takılan hastaların bağımlı olma nedeniyle rol performansında değişim, evin bakımını sağlamada yetersizlik ve depresyon yaşadığı bildirilmektedir. ${ }^{21,22}$ $\mathrm{Bu}$ çalışmada da literatürü destekler nitelikte bireyin TKP kaynaklı sosyal izolasyon ve rol performansında değişim, modifiye radikal mastektomi kaynaklı ise beden imajında bozulma yaşadığ 1 belirlendi.

\section{SONUÇ VE ÖNERİLER}

Sonuç olarak, olgu sunumu olarak ele alınan total kalça protezi ameliyatı sonrası yarı bağımlı olan yaşlı bireyin evde bakımında yaşadığı ve yaşayabileceği olası problemlerin belirlenmesi ve bu problemlerin çözümlenmesinde bireyselleştirilmiş Günlük Yaşam Aktiviteleri Modeli kullanımının bağımsızlı̆̆ı kazandırılması ve olası komplikasyonların önlenmesinde önemli bir model olduğu belirlendi. $\mathrm{Bu}$ modelin kullanılması ile bireyin yaşamış olduğu akut ağrı, konstipasyon, uyku örüntüsünde bozulma, sosyal izolasyon, bilgi eksikliği, beslenme örüntüsünde değişim, aktivite intolerans1, beden imajında bozulma gibi problemler elimine edildi ve venöztromboemboli riski azaltıldı. Düşme riski, rol performansında değişim ve günlük yaşam aktivitelerini yerine getirmede yetersizlik problemlerinin ise hala devam ettiği gözlemlendi.

Çalışmadan elde edilen sonuçlar doğrultusunda, cerrahi girişim uygulanan yaşlı bireylerde iyileşme sürecinin hızlandırılması, taburculuk sonrası günlük yaşam aktivitelerini bağımsız ve güvenilir bir 
şekilde yerine getirmeleri ve olası komplikasyonların önlenmesinde evde bakımın önemli bir yere sahip olduğu ve belirlenmesinde Roper, Logan, Tierney Günlük Yaşam kullanılması Aktiviteleri Modeli yaşlı bireylerin evde bakım gereksinimlerinin

\section{KAYNAKLAR}

1. World Health Organization (WHO) (2015) http://apps.who.int/iris/bitstream/handle/10665/186463/978924 0694811_eng.pdf;jsessionid=C4C5EBE22DD183174AE1B1F F2AD869A5?sequence=1 Erişim Tarihi: 01.04.2020

2. Gürler, H., Bayraktar, N. ve Erdil, F. (2017). Cerrahi Girișim Uygulanan Yaşlı Bireylerde Düşmelerin Önlenmesi, Türkiye Klinikleri J Surg Nurs-Special Topics, 3 (2), 124-129.

3. Centers for Disease Control (CDC) and Prevention. National Center for Injury Prevention and Control (2015). Preventing Falls: A Guide to Implementing Effective Community-Based Fall Prevention Programs, 2nd Edition

4. Cockayne, S., Pighills, A., Adamson, J., Fairhurst, C., Drummond, A., Hewitt, C, ... ve Torgerson, D.J. (2018). Can Occupational Therapist-Led Home Environmental Assessment Prevent Falls in Older People? A Modified Cohort Randomised Controlled Trial Protocol. Send to BMJ Open, 8 (9), e022488.

5. Sotoudeh, G.R., Mohammadi, R., Mosallanezhad, Z., Viitasara, E. ve Soares, J.J.F. (2018). The Prevalence, Circumstances and Consequences of Unintentional Falls Among Elderly Iranians: A Population Study. Arch Gerontol Geriatr. 79, 123-130.

6. Jagnoor, J., Keay, L., Jaswal, N., Kaur, M. ve Ivers, R. (2014) A Qualitative Study on The Perceptions of Preventing Falls As A Health Priority Among Older People in Northern India, Injury Prevention, 20 (1), 29-34.

7. Özkan, S. ve Adanaş, C. (2018). Femur Boyun Kırıklarında Güncel Yaklaşımlar Current Approaches in Femoral Neck Fractures. Van Tip Derg 25 (1), 76-81.

8. Autar, R. (2011). Evidence Based Venous Thromboprophylaxis in Patients Undergoing Total Hip Replacement (THR), Total Knee Replacement (TKR) and Hip Fracture Surgery (HFS), International Journal of Orthopaedic and Trauma Nursing, 15 (3), 145-154.

9. Açıksöz, S. ve Uzun, Ş. (2007). Total Kalça Protezi Uygulanan Bireylerin Günlük Yaşam Aktivitelerine Yönelik Evde Bakımda Karşılaşılan Güçlükler. C.Ü. Hemşirelik Yüksekokulu Dergisi, 11 (1), 8-16.

10. Reay, P. A., Horner, B., ve Duggan, R. (2015). The Patient's Experience of Early Discharge Following Total Hip Replacement. International journal of orthopaedic and trauma nursing, 19 (3), 131-139.
11. Bilik, Ö. (2017). Klinikten Eve Uzanan Yolculuk: Ameliyat Olan Hastaların Evde Bakımı, Ege Üniversitesi Hemşirelik Fakültesi Dergisi, 33 (1), 114-127.

12. Bobay, K.L., Jerokfe, T.A., Weiss, M.C. ve Yakusheva, O. (2010). Age Related Differences in Perception of Quality of Discharge Teaching and Readiness for Hospital Discharge. Geriatric Nursing, 31 (3), 178-187.

13. Roper, N., Logan, W.W. ve Tierney, A.J. (2000). The RoperLogan-Tierney Model of Nursing: Based on Activities of Living. Edinburgh: Churchill Livingstone.

14. Alligood, M.R. (2014). Nursing Theorists and Their Work, 8. Edition, Elsevier Inc., Riverport Lane St. Louis, Missouri.

15. Bulut, H. ve Güler Demir, S. (2017). Hemșirelik Teorileri ve Modelleri. Karadağ, A., Çalışkan, N., Göçmen Baykara, Z. (Ed.) İstanbul, Akademi Basın, ss: 532-570.

16. Bilgiç, S., Celikkalp, Ü. ve Sarıkaya, N. (2017). Nekrotizan Fasiitli Bir Olgunun Yaşam Modeli Doğrultusunda Tanılanması. Gümüşhane Üniversitesi Sağllk Bilimleri Dergisi, $6(4), 320-325$

17. Yao, D.H., Keswani, A., Shah, C.K., Sher, A., Koenig, K.M. ve Moucha, C.S. (2017). Home Discharge After Primary Elective Total Joint Arthroplasty: Postdischarge Complication Timing and Risk Factor Analysis. J Arthroplasty, 32 (2), 375380.

18. Neighbour, C. (2014). Improving Bowel Care after Surgery for Hip Fracture. Nurs Older People, 26 (10), 16-22.

19. Suwanpasu, S. ve Pongpaew, W. (2016). Predictors of HealthRelated to Quality of Life after Hip Surgery in Elderly Patients after Acute Care, Journal of Medical Research \& Health Education, 1 (1), 1-7.

20. Fielden, J.M., Scott, S. ve Horne, J.G. (2003). An Investigation of Patient Satisfaction Following Discharge After Total Hip Replacement Surgery, Orthopaedic Nursing, 22 (6), 429-436.

21. Montin, L., Suominen, T. ve Leino-Kilpi, H. (2002). The Experiences of Patients Undergoing Total Hip Replacement, Journal of Ortohopedic Nursing, 6, 23-29.

22. Saray Kilıc, H. ve Tastan, S. (2017). Development of Post Hip Replacement Comfort Scale. Applied Nursing Research, 38, $169-174$ 